\title{
Os Tucanos no Governo de São Paulo: o peso dos indicadores socioeconômicos municipais no voto em Geraldo Alckmin nas eleições de 2002, 2010 e 2014I
}

Jayane dos Santos Maia

\section{Resumo}

O sucesso eleitoral do PSDB e de seus candidatos no governo do estado de São Paulo vem de longa data. Este estudo visa contribuir com a discussão acerca da manutenção do poder por esse partido no referido estado. A pesquisa objetivou, a partir da consecução de modelos logísticos lineares generalizados (GLM), verificar se indicadores socioeconômicos interferem de algum modo na proporção de votos obtida nos municípios pelo candidato eleito em São Paulo para o cargo de governador. Foram utilizadas na pesquisa as eleições de 2002, 2010 e 2014, as quais têm em comum a vitória do tucano Geraldo Alckmin. O IDHM, o índice de Gini e o índice de envelhecimento estão entre as variáveis que apresentaram significância estatística. No entanto, os modelos estatísticos de cada ano eleitoral explicaram pouco da variação total das proporções de votos. Isso demonstrou que outros fatores, não relacionados à estrutura socioeconômica, repercutem no sucesso eleitoral de Alckmin em São Paulo.

Palavras-chave: Eleição. São Paulo. Governador. Índices socioeconômicos.

\section{Introdução}

No Brasil, São Paulo se destaca por vários aspectos. Trata-se do estado que, atualmente, possuindo o maior parque industrial entre todos os estados, é responsável pela maior participação no PIB nacional. Destaca-seainda por

I Quero agradecer as sugestões e os apontamentos feitos pelos pareceristas da revista Política E Sociedade, que foram essenciais para o melhoramento do artigo.

2 Mestre em Sociologia pela Universidade de Brasilia. Atualmente é doutoranda em Política Comparada no Instituto de Ciências Sociais da Universidade de Lisboa. E-mail: jayane.maia08@gmail.com. 
ter uma população diversa, advinda de diferentes origens: migrantes de outros estados brasileirose imigrantes de vários países ${ }^{3}$. É, portanto, o estado que possui a maior heterogeneidade populacional.

A significância do estado de Sáo Paulo, que vem desde os tempos coloniais, estende-se até hoje em diferentes aspectos, entre eles, na política nacional. Atualmente, o estado também chama atenção pela característica que une todos os seus governadores eleitos desde o pleito de 1994. Desde esse ano, com a vitória de Mário Covas, candidatos do Partido da Social Democracia Brasileira (PSDB) ocupam o Palácio dos Bandeirantes. Em 2018, o PSDB, ao que tudo indica, completará 24 anos à frente do governo do estado ${ }^{4}$, tendo em vista a eleição em primeiro turno de Geraldo Alckmin nas eleiçóes de 2014. Sáo Paulo se destaca ainda pelo maior número de mandatos de um mesmo partido, no caso o PSDB, no governo estadual. Perto dele há apenas o Acre, onde candidatos do principal rival, o Partido dos Trabalhadores (PT),vencem as eleiçóes para o governo acreano desde 1998.

O PSDB, hoje, possui grande visibilidade nacional, sendo um dos principais partidos brasileiros. Segundo dados do Tribunal Superior Eleitoral (TSE), em 2015 o partido foi o quarto colocado em número de filiados no Brasil, com 1.409.515 eleitores inscritos, estando atrás de PMDB, PT e PP. Só em São Paulo o partido, até abril de 2016, possuía 302.966 filiados, ocupando também a quarta colocação em número de inscritos, sendo, entre os cinco primeiros da lista, o partido que mais aumentou em filiados em São Paulo desde dezembro de 2015.

Nas últimas eleiçóes, obtevea vitória para o governo de cinco estados, os quais somam, juntos, uma população que representa mais de $1 / 3$ do total de habitantes do país. Na Câmara Federal o partido é,atualmente, o terceiro

3 Segundo dados da Pesquisa Nacional de Amostras por Domicílio (PNAD) relativos ao ano de 2013, São Paulo é o estado que possui o maior número de migrantes, com mais de 10 milhões. Já de acordo com o Sistema Nacional de Cadastramento e Registro de Estrangeiros (Sincre), mais da metade dos estrangeiros registrados no Brasil estão no estado de São Paulo, o que corresponde a 561.912 imigrantes. A Polícia Federal registrou que portugueses, bolivianos e japoneses somam 177.908 habitantes apenas na capital paulista. Eles formam, nessa ordem, as três maiores comunidades de imigrantes na cidade.

4 Mais detalhadamente, o PSDB poderá completar a frente do governo de SP 23 anos e três meses. Isso porque, em 2006, houve uma interrupção de nove meses, quando Geraldo Alckmin deixou o governo para disputar a eleição presidencial. Em seu lugar assumiu o seu vice, Claudio Lembo, filiado ao então Partido da Frente Liberal (PFL). 
colocado no número de cadeiras, tendo 54 deputados. Além disso, está no comando de 702 prefeituras, ficando atrás apenas do PMDB que tem 1.031. Criado em 1988, no período da Assembleia Nacional Constituinte, o PSDB foi formado por dissidentes do PMDB como Mário Covas, Fernando Henrique Cardoso, André Franco Montoro, Luiz Carlos Bresser Pereira, Geraldo Alckmin, José Serra e José Richa.Entre os 116 fundadores do partido, segundo a ata da reuniáo de fundaçáo, 35 eram paulistas, o que correspondia à maioria de representantes de um estado.

Personagem importante na política paulista, Geraldo Alckmin destaca-se por ser o candidato tucano que mais ocupou o cargo de governador de SP: foi eleito em 2002, 2010 e 2014. Foi ainda duas vezes vice-governador, com a vitória em 1994 e 1998 de Mário Covas(seu principal cabo eleitoral), tendo-o substituído a partir de março de 2001, após sua morte. Alckmin iniciou sua carreira política como vereador em Pindamonhangaba, sua cidade natal, e se podedizer que as suas vitórias para o Executivo estadual paulista certamente para o seu estabelecimento como uma das lideranças atuais do PSDB.

Tendo em vista a relevância de São Paulo, as consecutivas eleições do PSDB para o governo estadual e a emergência de Alckmin como uma liderança política nacional, esse estudo se propóe a analisar as eleiçóes nas quais Geraldo Alckmin foi eleito governador de São Paulo, a fim de contribuir com a discussão acerca da participação e permanência do PSDB no governo paulista bem como com os debates gerais acerca de reeleição no Brasil. Perguntando-se sobre o que leva o PSDB a se reeleger continuadamente para o governo de São Paulo e, mais especificamente,se variáveis socioeconômicas municipais como IDH e índice de envelhecimento corroboram de forma positiva para o ganho de votos por Alckmin e sustentam sua eleição, analisar-se-âo aqui as proporçôes de votos por município das eleiçóes nas quais ele foi o vitorioso para o Executivo paulista nos anos de 2002, 2010 e 2014.

Ao tratar de eleiçóes, embora seja praticamente impossível não mencionar aqueles que são responsáveis por elas, isto é, os eleitores, a pesquisa não objetiva entender o comportamento eleitoral do votante paulista nem definir o perfil dos eleitores que votam ou votaram em Alckmin e no PSDB. Logo, não se almeja aqui explicitar os determinantes do voto do eleitor, mas sim investigar se fatores sociais e econômicos estão ligados à inserção exitosa de Alckmin e de seu partido no governo de Sáo Paulo. 
A investigação da possibilidade de haver um padrão no perfil dos votantes em Alckmin nos anos em que ele foi eleito é uma forma de medir até que ponto aspectos como educaçáo, renda e idade de uma populaçáo interferem e pesam na votação dada a um candidato e a seu partido. A identificação de um reduto eleitoral ou de uma base de apoio que favoreça em Sáo Paulo a vitória tucana é importante na medida em que mostra qual ou quais grupo(s) tende $(\mathrm{m})$ a preferiros candidatos peessedebistas ou a rejeitar as opçóes dadas contra o governo.

No campo da sociologia eleitoral, o estudo das reeleiçóes e da dinâmica política que as envolve ainda carece de contribuiçóes, o que também ocorre com os estudos acerca do ambiente dos governos estaduais. Pesquisas relacionadas ao Poder Legislativo e aos governos municipais ainda sobressaem, juntamente com trabalhos que tratam do Poder Executivo federal (LIMONGI; GUARNIERI, 2015; JACOB; HEES; WANIEZ; BRUSTLEIN, 2003; SOARES; TERRON, 2008; CERVI, 2009; ALMEIDA; LOPEZ, 2012).

Não havendo estudos significativos publicados sobre questóes políticas e eleitorais que abarquem o estado de São Paulo, com exceção dos trabalhos de Roma (2000), Braga (2008) e Storni (2010), as eleiçóes municipais da capital do estado sáo protagonistas em boa parte dos trabalhos (FERREIRA, 1960; LAMOUNIER, 1975; MARQUES, 2003; LIMONGI; MESQUITA, 2011). Talvez se possa justificar a preferência pelo município em detrimento do estado tendo em vista a enorme complexidade que é tratar das eleiçóes para governador num estado que tem o maior número de municípios e tantas diversidades. Há, portanto, uma lacuna considerável quando se trata da eleição do governo dos estados e, nesse sentido, esse trabalho aborda também esse aspecto.

\section{O papel das clivagens sociais nas arenas política e eleitoral}

A associação entre indicadores socioeconômicos e resultados eleitorais é, há algum tempo, uma prática comum entre os estudiosos que pretendem verificar quais as bases de apoio de um ou outro candidato. A ideia da existência de um reduto eleitoral que apoie um político ou um partido e que seja decisivo para seu sucesso é defendida por muitos (FERREIRA, 1960; LAMOUNIER, 1980; PIERUCCI, 1989) e podese basear em padróes de voto encontrados em localidades geográficas bem como em populaçóes que compartilham características semelhantes. 
Vários estudos foram feitos nesse sentido, abarcando especificamente o contexto eleitoral da cidade de São Paulo, e não do estado. Acredita-se, no entanto, que as ideias e conclusōes advindas desses trabalhos são de grande valia para ilustrar o que tem sido produzido até o momento nesse campo e, mais importante, para mostrar ao longo dos anos quais clivagens foram consideradas e colocadas em primeiro plano por diferentes autores.

Aziz Simão, em trabalho intitulado "O voto operário em São Paulo" (1956),estuda a distribuição do voto operário entre o eleitorado paulista nas eleições de 1947 para as assembleias estaduais. A partir da divisão da cidade em quatro zonas eleitorais majoritariamente operárias ${ }^{5}$, o autor observou que o Partido Comunista do Brasil (PCB) e o Partido Trabalhista Brasileiro (PTB) foram os partidos principais entre os quais se dividiram os votos dessas regióes. Segundo Simão, o eleitorado do PCB incluía pessoas nascidas na capital, as quais residiam, em grande parte, nos antigos bairros industriais, destacando-se os homens entre 18 e 40 anos, trabalhadores em serviços especializados. Já o PTB tinha como eleitores pessoas advindas das zonas ruraisnos anos 40, as quais estavam empregadas menos em fábricas e mais em serviços que exigiam pouca ou nenhuma qualificação profissional nas áreas de pequenos ofícios, construção civil e transportes. Segundo o autor, o eleitorado petebista, principalmente aquele originário do êxodo rural, via a legislaçáa trabalhista de Getúlio Vargas com bons olhos e retribuía isso votando em seu partido. Nesse sentido, para Simão, a clivagem urbano-rural era fundamental para entender as bases de apoio dos partidos.

O trabalho de Oliveiros Ferreira, intitulado "Comportamento Eleitoral em Sáo Paulo" (1960), que foca igualmente a divisão rural versus urbano, como fez Simáo, analisou, além das eleiçóes para senador e deputado estadual e federal em 1958, as eleiçóes para o governo do estado nesse ano e em 1954, considerando, para isso, também a estrutura socioeconômica.

5 A primeira zona, que margeava o que Simão denominou de Y ferroviário, reunia o maior eleitorado operário da cidade de São Paulo com 68\% e compreendia dezenove distritos, sendo que entre eles estavam Ipiranga, Mooca, Brás, Tatuapé, Penha, Bom Retiro, Barra Funda e Lapa. A segunda zona, por ser mais afastada do eixo ferroviário e possuir ocupação recente, abrangia $7 \%$ do total de eleitores operários da capital, os quais estavam divididos nos distritos de Santo Amaro, Indianópolis, Ibirapuera e Saúde. A terceira zona classificada pelo autor de "suburbana" concentrava somente $4 \%$ dos eleitores operários divididos entre Itaquera, Baquirivu, Guaianases, Pirituba, Perus e Osasco. Por fim, a quarta zona inclui três distritos (Butantã. Capela do Socorro $e$ Parelheiros) que abarcavam 1,21\% do total do eleitorado operário. 
A clivagem urbano-rural foi trabalhada pelo autor a partir do índice de industrialização do município, o que permitiu o agrupamento desses em três zonas diferentes. No pleito de 1954, Jânio Quadros, que concorreu pelo pequeno Partido Trabalhista Nacional (PTN), venceu Adhemar de Barros, do Partido Social Progressista (PSP), que era o candidato do governo apoiado tanto pelo PTB quanto pelo agora ilegal PCB. Segundo Ferreira, Jânio, com um discurso pautado pela impessoalidade e eficiência administrativa,obteve mais votos na zona com maior índice de industrialização, enquanto o seu adversário, enfatizando a tradição e a manutenção do status quo, perdia votos à medida que a região se tornava mais industrializada/urbanizada.

Em 1958, Barros perdeu novamente, mesmo contando com a estrutura montada pelos partidos aliados tanto na capital quanto no interior do estado - desta feita, para Carvalho Pinto, do Partido Democrata Cristáo (PDC), que, sendo apoiado por Jânio, apropriou-se de seu discurso da campanha anterior. Para Ferreira, o padrão de votação nas três áreas era claro: o voto na oposição ocorria nas regióes mais industrializadas e o contrário acontecia com relação ao voto no governo. Segundo Francisco Weffort, seria plausível a hipótese “[...] segundo a qual Jânio Quadros tenderia a expressar politicamente os setores assalariados - operários e classe média assalariada - mais integrados no desenvolvimento capitalista, diversamente de Adhemar de Barros, que daria expressão a camadas marginais a este processo, em particular pequenos proprietários e setores assalariados de tipo lúmpen" (WEFFORT, 1965, p. 56).

No tocante ao período da ditadura militar, Bolívar Lamounier,no artigo "Comportamento Eleitoral em Sáo Paulo: passado e presente" (1975) vinculou voto e posição socioeconômica a partir do estudo que fez das eleiçôes legislativas na cidade de SP, mais especificamente, da votação de Orestes Quércia, candidato ao Senado pelo Movimento Democrático Brasileiro (MDB). Lamounier, utilizando método semelhante aos utilizados pelos autores já citados, dividiu o mapa da capital em quatro áreas diferentes de acordo com a votação de Quércia, o que indicou que os votos ao MDB aumentavam quanto maior e mais periférica fosse a área. Os dados organizados pelo autor mostravam ainda que o MDB era a escolha principal (80\%) entre os

6 Lúmpen é um termo utilizado para designar assalariados de remuneração extremamente baixa. Segundo Bolivar Lamounier (1980), as pessoas de baixissima renda votariam tanto na ARENA quanto no MDB. 
eleitores que eram empregados domésticos, ambulantes ou que trabalhavam ocasionalmente. Essa porcentagem caía para $60 \%$ entre operários qualificados e trabalhadores manuais com baixos salários e para $48 \%$ entre empregadores - administradores, proprietários e gerentes. Dessa forma, o MDB, partido de oposição ao governo, estaria associado aos mais pobres, enquanto a ARENA se relacionaria com os mais ricos. Segundo o autor, a vinculação entre diferenciaçóes socioeconômicas e voto "[...] desqualifica a hipótese de um comportamento caótico ou puramente clientelista" (LAMOUNIER, 1975, p. 22). Em outro trabalho intitulado "O voto em São Paulo, 1970-1978", Lamounier, valendo-se da divisão social pautada pela idade, apontou que os mais jovens tenderiam a votar no MDB, enquanto os mais velhos se inclinariam a votar na ARENA.

Após a ditadura, período no qual os governadores e prefeitos eram indicados aos cargos, Jânio Quadros foi eleito prefeito de Sáo Paulo (1/1986 a 12/1988); posteriormente, vieram Luiza Erundina, do Partido dos Trabalhadores (1/1989 a 12/1992) e Paulo Maluf, do então Partido Democrático Social (1/1993 a 12/1996). Antônio Flávio Pierucciem "São Paulo 92, a vitória da direita" (1993) mostra a emergência na capital da polarização entre a esquerda petistae a direita malufista.Descreve essa polarização a partir de regióes socioeconômicas da cidade e aponta que o PT se fortaleceu na capital graças aos votos de bairros periféricos e carentes, mobilizandoo eleitorado mais pobre da periferia paulistana bem como alguns eleitores progressistas das classes médias e médias altas. Já Maluf começou a ganhar votos entre os distritos da classe média baixa e entre os eleitores de classe alta.

Segundo Limongi e Mesquita (2008), as oscilaçôes da prefeitura de São Paulo entre esquerda e direita são explicadas pelo fato de que, devido ao alto grau de polarização ideológica, as vitórias de um ou outro lado seriam decididas pelos eleitores de centro, os quais votariam de acordo com fatores de curto prazo. Ao analisarem as eleiçóes para a prefeitura da capital de 1985 até 2004, ano da vitória de José Serra (PSDB), objetivando "[...] caracterizar o apoio aos diferentes partidos ao longo do tempo" (LIMONGI; MESQUITA, 2008, p. 51), os autores apontam que o PT, a partir da vitória de Maluf nas eleiçóes de 1992, começou a ser visto como um partido de oposiçáo apoiado, na capital, principalmente pelos eleitores de baixa renda e baixo grau de escolaridade. Conforme aponta Rocha (2012, p. 277), “[...] São Paulo [a cidade] acolheu o 
PT, entre idas e vindas, como o principal partido de esquerda oposicionista, que mobiliza, atualmente, sobretudo as camadas trabalhadoras mais empobrecidas”. Já o PSDB, que ganha força após a decadência de Maluf, é apoiado especialmente por eleitores com maior educação e renda.

Teoricamente, os partidos políticos são essenciais em uma democracia devido à função que exercem de representação da população seja nas arenas eleitoral ou legislativa. Basicamente, de acordo com essa perspectiva, a vida útil das organizaçóes partidárias está atrelada à sua capacidade de agregar interesses e fazê-los refletir politicamente. Mesmo que na realidade os partidos sejam fruto menos da necessidade de representaçáo dos cidadáos e mais da divergência entre indivíduos políticos - choque de vaidades e egos - e da necessidade de sobrevivência política, eles são os responsáveis por estruturar o contexto eleitoral, e fazem isso a partir da formação de alianças e da agregação dos interesses dos eleitores, o que se torna fundamental para o sucesso eleitoral. Dessa forma, os partidos estão longe de ser apenas abstraçóes jurídico-institucionais que possuem relevância apenas no meio parlamentar, de modo que seria compreensível se, no âmbito eleitoral, eles, em face de seu caráter representativo, se organizassem a partir das divisóes sociais existentes.

Mesmo que clivagens como raça, renda, regiáo, gênero e religião sejam exemplos de temas conflituais que, no Brasil, ainda suscitam preconceitos e desigualdades e que, portanto, poderiam ser articulados por partidos e políticos de forma específica para funcionar como catapultas eleitorais, o investimento eleitoral em um grupo particular não é uma estratégia política comum. Nesse cenário, a disputa eleitoral é orquestrada pela elite política, sobre bases formadas por fatores de curto prazo e propostas programáticas criadas a partir de temas que são mobilizados pelos candidatos no decorrer da campanha, a depender da temática dos deslizes cometidos por quem está no governo, que certamente serão explorados pelos adversários, ou de qual seja a questáo que esses últimos dominam para se impor no debate. Com efeito, as diferenças entre os candidatos, quando existem, baseiam-se em aspectos voláteis e não estruturais, tática para captar o maior eleitorado possível, o que faz com que os partidos acabem lutando pela mesma faixa de eleitores.

Nas eleiçóes de 2002 para o governo paulista, por exemplo, a questão da violência e segurança pautou boa parte da campanha política dos candidatos, devido tanto a fatores ocasionais quanto à facilidade do candidato Paulo 
Maluf (PPB) de mobilizar em seu discurso esse tema e captar eleitores preocupados com ele. $\mathrm{O}$ resultado foi que os outros dois principais candidatos, Geraldo Alckmin (PSDB) e José Genoíno (PT), também se voltaram para essa questão, na tentativa de adentrar no terreno seguro de Maluf e competir com este pelos votos desse eleitorado. A campanha política de Alckmin se voltou com afinco para o interior de Sáo Paulo, tendo em vista que segundo pesquisas encomendadas pelo PSDB, lá estavam os eleitores mais vulneráveis ao discurso de Maluf sobre segurança.

Ainda que existam estudos de sociologia eleitoral que apontem e comprovem a heterogeneidade e indiferenciação social das bases eleitorais das organizaçooes partidárias (GASPAR; ANDRÉ, 1989; FREIRE, 2001; AMES, 2003; LISI, 2011), isso não significa dizer que os partidos não sejam capazes, mesmo utilizando estratégias políticas voltadas para um eleitorado amplo, de mobilizar e estruturar o voto de um tipo de eleitor em particular. A peculiaridade desse grupo de eleitores pode não estar em consonância com as linhas ideológicas ou programáticas do partido e sim naqualidade de simpatizantes, ou seja, de eleitores que simplesmente apoiam ou se identificam com o partido e/ou com seu candidato (WHITELEY; SEYD, 2002).

Se a ideologia não tem hoje no Brasil grande peso na distribuição dos votos nos partidos políticos e em seus candidatos, é possível que os eleitores simpatizantes formem um grupo homogêneo em termos socioeconômicos e geográficos o suficiente para permitir que eles interfiram potencialmente nos resultados eleitorais. Mesmo que os principais partidos brasileiros sejam organizaçôes interclassistas, competindo por bases eleitorais semelhantes e heterogêneas, deve-se considerar a possibilidade de que, dentro dessa heterogeneidade, estejam grupos de eleitores que compartilham características (idade, educação, renda, localização geográfica etc.) e que podem pesar no sucesso eleitoral de uma candidatura.

\section{Voto e índices socioeconômicos: as hipóteses de pesquisa para as bases de apoio de Geraldo Alckmin}

No caso das eleições de Geraldo Alckmin para o governo de São Paulo, considerando a possível relevância dos índices sociais e econômicos nos resultados eleitorais, a primeira hipótese é a de que variáveis socioeconômicas 
relativas aos municípios paulistas interferem na votação de Alckmin na localidade, aumentando-a ou diminuindo-a. Mais especificamente, desejou-se verificar se o aumento do Índice de Desenvolvimento Humano Municipal (IDHM) favorece uma distribuição positiva do voto em Alckmin no município, contribuindo para o seu êxito eleitoral no estado. Como esse índice inclui escolaridade, renda e longevidade, pretende-se testar se o aumento dessas três variáveis em conjunto aumenta a possibilidade do voto no governo. Esse pressuposto baseia-se principalmente em achados de autores que se debruçaram em seus estudos sobre a relação entre os partidos políticos e suas bases eleitorais e o perfil dessas.

Marco Lisi (2011), em seu trabalho sobre os partidos políticos em Portugal, salienta que o peso dos votantes mais idosos - aqueles com mais de 55 anos nas organizaçóes partidárias passou nos últimos anos de aproximadamente 1/3 do eleitorado para cerca de $40 \%$, especialmente quando se trata dos partidos que ocupam o governo e daqueles localizados à direita do espectro ideológico. $\mathrm{O}$ autor considera que esse processo está intimamente relacionado ao gradual envelhecimento da sociedade e com o relativo afastamento da camada mais jovem da populaçáo da arena política, o que culmina na dificuldade dos partidos em estruturar seus votos (LISI, 2011). Ao analisar a evolução etária das bases dos partidos portugueses, o autor aponta que "o declínio mais evidente dos grupos etários mais novos registra-se no PSD (Partido Social Democrata), em que a percentagem dos eleitores com menos de 34 anos passou de quase $34 \%$ em 1984 para cerca de 25\% em 2005” (LISI, 2011, p. 106).

O autor demonstra ainda que os eleitores dos partidos de centro-direita tendem a possuir grau de educação mais elevado que os dos partidos de esquerda. Em Portugal, o Partido Social Democrata e o Partido do Centro Democrático Social (CDS), ambos considerados de centro-direita, possuem as maiores proporçôes de eleitores com nível educacional elevado (LISI, 2011). Cerca de 30\% dos eleitores do CDS tem um curso (ou frequência) de licenciatura, de modo que "esta percentagem é, no caso dos partidos de esquerda, equivalente a cerca de um quinto dos respectivos eleitorados" (LISI, 2011, p. 107). No que se refere ao Partido da Social Democracia Brasileira (PSDB), considerado por muitos autores um partido de centro ${ }^{7}$, a sua aliança, no caso

7 Oficialmente, o PSDB se autodenomina um partido de centro-esquerda, o que se percebe pelo que está colocado no artigo segundo do seu estatuto: "O PSDB tem como base a democracia interna e a disciplina e, como objetivos 
do Poder Executivo paulista, com partidos localizados à direita do espectro ideológico, em especial com o antigo PFL - hoje Democratas -, motivou a construção dessa hipótese nessa direção.

Jairo Nicolau (2014), ao investigar os efeitos de variáveis socioeconômicas sobre o desempenho de candidatos petistas e peessedebistas à Presidência da República, vai de encontro, em certa medida, aos apontamentos feitos por Lisi (2011). Nicolau mostra que, nas eleiçóes de 2006, enquanto Lula (PT) teve melhor desempenho eleitoral nos municípios com menor IDH, Alckmin (PSDB) teve sua votação aumentada nas cidades com maior IDH. No entanto, analisando a disputa entre Dilma Rousseff (PT) e José Serra (PSDB) nas eleiçóes de 2010, o autor aponta que a votaçáo do PSDB passou a estar associada negativamente ao IDH, ao passo que o efeito do índice na votação de Dilma não foi estatisticamente significante.

Supóe-se também que quanto menor for a desigualdade de renda entre a populaçáo e maior for a taxa de empregos formais no município, a votação em Alckmin terá distribuiçáo positiva. Sabe-se que aspectos relativos ao contexto político e ao diaadia dos eleitores são passíveis de influenciar o seu comportamento quanto à tomada de decisão do voto. $\mathrm{O}$ contentamento da populaçáo com a sua qualidade de vida, o que inclui desde boas condiçóes de infraestrutura - transporte público, iluminaçáo, estradas - até o melhoramento da educação, saúde e segurança, bem como o aumento das vagas de emprego, certamente possui um peso significativo na vitória de quem ocupa o governo.

Para citar um caso, basta lembrar que a reeleição, em 1998,de Mário Covas, que tinha Alckmin como candidato a vice, quase foi prejudicada por altas taxas de desemprego e criminalidade, que foram consequências de medidas de austeridade implantadas no primeiro mandato, a fim de controlar um desequilíbrio fiscal iniciado no governo antecessor, o que resultou no bloqueio dos gastos públicos. Esse é um exemplo de como problemas que sáo náo apenas mostrados numericamente, mas sentidos no diaadia dos cidadáos,podem afetar negativamente as pretensóes eleitorais de atores políticos que se encontram no governo.

programáticos [...] a construção de uma ordem social justa e garantida pela igualdade de oportunidades [...] e a realização do desenvolvimento de forma harmoniosa, com a prevalência do trabalho sobre o capital, buscando a distribuição equilibrada da riqueza nacional entre todas as regiões e classes sociais". Ver estatuto completo em:<http://static.psdb.org.br/wp-content/uploads/2016/02/Estatuto\%202015_12_final.pdf>. 
De outro lado, o projeto obreiro de governantes, que se resume na feitura ou na inauguração de obras feitas às vésperas de uma eleiçáo, pode ter consequências tanto para o bem, possuindo alta capilaridade eleitoral, quanto para o mal. Nas eleiçóes de 2014, Alckmin náo venceu em apenas um dos 645 municípios do estado: Hortolândia, que dista cerca de 110 quilômetros da capital. Muitas causas foram atribuídas à derrota tucana nesse município, e entre elas estava o fato de que na gestáo do PSDB na prefeitura houve a construção do complexo penitenciário Professor Ataliba Nogueira, apelidado de "Carandiru Caipira", por ter recebido a maior parte dos presos da antiga Casa de Detenção de São Paulo, quando da sua desativação em 2002. Embora esse caso fizesse parte do passado, a populaçáo hortolandense o considerou parte de um passado recente, que parece ter ficado ainda mais vivo quando o governador do estado anunciou em 2005 a instalação da Fundação Casa - antiga Fundação Estadual do Bem-Estar do Menor (FEBEM) - no município, o que acarretou uma série de protestos e manifestaçóes, obrigando Alckmin a voltar atrás na decisão. Nessa época, a gestão de Hortolândia já tinha passado para as máos do PT e o sucesso do prefeito petista, reforçado pelos deslizes cometidos pelos tucanos, também foi avaliado como uma das causas para a única derrota de Alckmin em $2014^{8}$.

Dado o papel-chave do prefeito nas eleiçóes estaduais, já que o mesmo funciona como cabo eleitoral de candidatos a deputado, governador e até mesmo presidente, também foi incluída na análise das vitórias de Geraldo Alckmin a variável política referente ao prefeito do município. Verificou-se se a votaçáo dada a Alckmin foi afetada em alguma medida pelo fato do prefeito ser de partido aliado ao governo ou pertencente à oposição. Teoricamente, diante da personificação do partido no prefeito, o mais provável seria que a votaçáo diminuísse nos municípios que contam com prefeitos que compóem partidos da oposiçáo.O pressuposto é o de que o prefeito tenda a utilizar a máquina municipal em benefício do candidato que ele apoia para governador, o qual, normalmente, é aquele que o seu partido lança.

Assim como a personificação do partido no prefeito pode ajudar ou prejudicar os candidatos ao Poder Executivo estadual, as políticas, sejam aquelas

8 Essas informações foram retiradas da matéria intitulada "Em Hortolândia, o PSDB não tem vez" escrita pela jornalista Marsilea Gombata e publicada on-line na revista Carta Capital em 14 out. 20I4. Ver em:<http:// www.cartacapital.com.br/politica/em-hortolandia-o-psdd-nao-tem-vez-7597.htmls. 
criadas pelo governo, sejam pela oposição, também podem influir no comportamento do eleitor e beneficiar uma ou outra parte, a depender de quem o eleitorado entende ser o seu criador. O Programa Bolsa Família, instituído em 2003 pelo então governo federal petista, é um programa de transferência de renda comumente associado ao Partido dos Trabalhadores e, por essa razão, considerado um instrumento de ganho de votos para seus integrantes. Estudos comprovam que a cobertura do Programa Bolsa Família (PBF), isto é, a proporção de famílias que são beneficiadas no município, associa-se positivamente, por exemplo, com a votação obtida por Lula nas eleiçóes de 2006 (ZUCCO, 2008; NICOLAU, 2014; LIMONGI; GUARNIERI, 2015).

Limongi e Guarnieri (2015), embora ressaltem que essa relação positiva náo comprova que o Bolsa Família seja o fator determinante para explicar o comportamento do eleitor em benefício do PT, concluíram que em 2006 a relação entre a cobertura da política e o voto em Alckmin, concorrente nesse ano à presidência pelo PSDB, era inversa a que ocorria com Lula. Nicolau (2014) também chega a essa mesma conclusão tanto para a eleição de 2006 quanto para a de 2010. Dilma, ao contrário de Serra, tende a ser mais votada nos municípios com maior número de famílias atendidas pelo programa.

Outro achado importante de Limongi e Guarnieri (2015) aponta para pesos diferentes do programa nos estados brasileiros quanto à captação de votos pelo PT. Os autores mostram que em São Paulo, nas eleiçóes de 2006, a relação entre voto em Lula e Bolsa Família é mais direta que, por exemplo, no Maranhão. Isso significa que no caso maranhense, mesmo nas localidades onde a cobertura do PBF era baixa, Lula obteve bons resultados, ao passo que em Sáo Paulo "quanto mais famílias no Programa, maior a votação em Lula.[Já] Nos municípios [paulistas] onde não há famílias cobertas pelo Programa, a vantagem de Alckmin sobre Lula é superior a 30\%" (LIMONGI; GUARNIERI, 2015, p. 73). Conclusão semelhante aparece no estudo de Martins, Mansano, Parré e Plassa (2016), o qual evidencia que o efeito positivo do programa sobre a votação de Dilma, em 2014, foi maior nos municípios das regiôes Sul e Sudeste.

Com efeito, é visando medir a influência do alcance do Bolsa Família na votação atribuída à Alckmin e ao PSDB na competição pelo governo paulista que o número de famílias beneficiadas em cada município foi incluído como variável nesse estudo. A hipótese é de que ocorra no pleito estadual aquilo que Limongi e Guarnieri encontraram nas eleiçôes federais: a votação em Alckmin é menor nos municípios com mais famílias atendidas pelo PBF. 


\section{Metodologia}

A unidade de análise da pesquisa são os 645 municípios do estado de São Paulo. As variáveis mostradas na Tabela 10.1 foram selecionadas por município paulista, a fim de compor a investigaçáo sobre o êxito eleitoral de Geraldo Alckmin nas eleiçôes de 2002, 2010 e 2014 em relação a variáveis socioeconômicas, ressaltando que os dados eleitorais de 2002 correspondem ao segundo turno. Para cada ano eleitoral foi construído um modelo logístico lineargeneralizado (generalized linear model-GLM), obedecendo-se as premissas de linearidade, aleatoriedade e normalidade.

Os dados eleitorais foram obtidos no site do Tribunal Superior Eleitoral (TSE) e os indicadores socioeconômicos tiveram como fonte as informaçóes do Instituto Brasileiro de Geografia e Estatística (IBGE) bem como da Fundação Sistema Estadual de Análise de Dados (SEADE).Assumiu-se que a proporção de votos em Geraldo Alckmin seja uma combinação de fatores socioeconômicos, os quais, destacados por ano eleitoral, correspondem às variáveis independentes ${ }^{9}$ descritas abaixo:

Tabela 10.I - Variáveis independentes utilizadas

nos modelos relacionadas por ano eleitoral

\begin{tabular}{ll}
\hline Ano eleitoral & Variáveis Independentes \\
\hline 2002 & $\begin{array}{l}\text { IDHM* (2000), taxa de analfabetismo, índice de envelhecimento, índice de Gini } \\
\text { (2000), Índice Paulista de Responsabilidade Social - escolar (IPRS escolar)**, } \\
\text { partido do prefeito, número de empregos formais }\end{array}$ \\
& $\begin{array}{l}\text { IDHM, taxa de analfabetismo, índice de envelhecimento, índice de Gini, Índice } \\
2010 \\
\text { Paulista de Responsabilidade Social - escolar (IPRS escolar), partido do prefeito, } \\
\text { número de empregos formais, número de famílias que recebem Bolsa Família }\end{array}$ \\
& $\begin{array}{l}\text { Taxa de abandono ensino médio (20 I2), PIB per capita, índice de } \\
\text { envelhecimento, partido do prefeito, número de empregos formais, número de } \\
\text { famílias que recebem Bolsa Família }\end{array}$ \\
\hline
\end{tabular}

* Índice de Desenvolvimento Humano Municipal. ** O Índice Paulista de Responsabilidade Social (IPRS) é um indicador que, semelhante ao IDH, tem a finalidade de medir a qualidade de vida da população paulista, incluindo as dimensões de escolaridade, rendimento e longevidade. Foi elaborado pela Fundação Sistema Estadual de Análise de Dados (SEADE).

Fonte: elaboração da autora

9 As estatísticas descritivas das variáveis utilizadas nos modelos estão dispostas no apêndice (Tabela A.I), ao final do artigo. 
Tendo em vista a dificuldade de se encontrar, em alguns casos, índices socioeconômicos que correspondessem exatamente ao ano em que houve eleiçôes, foram feitas aproximaçóes, utilizando-se dados disponibilizados de anos próximos. As variáveis que não correspondem ao ano eleitoral em questáo têm o seu ano equivalente mostrado entre parênteses na Tabela 10.1. Além disso, algumas variáveis relativas aos anos de 2002 e 2010 não foram encontradas disponíveis para o ano de 2014; por isso, a fim de se aferir educaçáo e renda, foram escolhidos outros indicadores: taxa de abandono do ensino médio e PIB per capita.

Cabe ressaltar ainda que tanto o número de famílias beneficiadas pelo Programa Bolsa Família quanto o número de empregos formais, por representarem variáveis com valores absolutos por município, foram transformadas em porcentagem, utilizando-se, para tanto, a população do município no ano respectivo. Após isso, a variável proporção de empregos formais foi transformada para logaritmo neperiano, a para que fosse mantida a premissa de linearidade. Pelo mesmo motivo, o mesmo procedimento foi feito com a variável PIB per capita.

Os resultados dasregressóes estatísticas derivaram da estimativa dos coeficientes associados a cada variável e do teste posterior, que revelou se os valores encontrados eram estatisticamente significativos ou náo. Os valores de $p$ foram considerados significativos abaixo de 0,05 , como pode ser observado na tabela 2, abaixo.

\section{Resultados}

Ao se analisar os resultados do modelo relativo ao ano de 2002, em que ocorreu a primeira eleição de Alckmin para o governo de Sáo Paulo, três variáveis se mostraram estatisticamente significantes: IDHM (2000), índice de Gini (2000) e índice de envelhecimento. Mantendo-se constantes todas as demais variáveis do modelo, tem-se que,quanto maior foi o Índice de Desenvolvimento Humano no município,a proporção de votos no candidato tucano tendeu a diminuir, demonstrando uma relação inversamente proporcional entre IDHM e voto em Geraldo Alckmin, conforme evidencia a Tabela 10.2 , abaixo.Infere-se que municípios com maior grau de desenvolvimento no conjunto das dimensóes de escolaridade, renda e longevidade náo apresentaram tendência em votar no candidato tucano na sua primeira eleição para o Executivo paulista. 
O índice de envelhecimento, que indicaa longevidade do município, também foi significativo estatisticamente no modelo de 2002. Quanto maior o grau de envelhecimento da populaçáo do município, houve um aumento na proporçáo de votos, mantendo-se as outras variáveis constantes (Tabela 10.2).

Tabela $\mathbf{1 0 . 2}$ - Resultados dos modelos lineares generalizados (GLM) por ano eleitoral'

\begin{tabular}{|c|c|c|c|c|c|}
\hline Modelo & Variáveis & Coeficientes & $\begin{array}{l}\text { Erro } \\
\text { padrão }\end{array}$ & $t$ & $p$ \\
\hline \multirow{8}{*}{$\begin{array}{l}\text { Eleição } \\
\text { 2002* }\end{array}$} & Intercepto & 60,162 & 8,349 & 7,206 & $<0,001$ \\
\hline & IDHM 2000 & $-32,693$ & 13,528 & $-2,417$ & $<0,05$ \\
\hline & Taxa de analfabetismo & 0,182 & 0,153 & 1,185 & 0,236 \\
\hline & Índice de envelhecimento & 0,137 & 0,027 & 5,07 & $<0,001$ \\
\hline & Gini 2000 & 28,255 & 5,562 & 5,08 & $<0,001$ \\
\hline & IPRS escolar & $-0,062$ & 0,05 & $-1,238$ & 0,216 \\
\hline & Partido prefeito eleito em 2000 & $-0,283$ & 0,613 & $-0,46 \mid$ & 0,644 \\
\hline & Log (prop. empregos formais) & 0,41 & 0,689 & 0,595 & 0,551 \\
\hline \multirow{9}{*}{$\begin{array}{l}\text { Eleição } \\
2010^{* *}\end{array}$} & Intercepto & 151,307 & 13,106 & 11,545 & $<0,001$ \\
\hline & IDHM 2010 & $-161,226$ & 18,113 & $-8,901$ & $<0,001$ \\
\hline & Taxa analfabetismo & $-0,538$ & 0,194 & $-2,778$ & $<0,0$ I \\
\hline & Índice de envelhecimento & 0,146 & 0,019 & 7,792 & $<0,001$ \\
\hline & Gini 2010 & 19,827 & 6,799 & 2,916 & $<0,01$ \\
\hline & IPRS escolar & 0,089 & 0,046 & 1,953 & $<0,1$ \\
\hline & Partido Prefeito eleito em 2008 & $-0,447$ & 0,655 & $-0,682$ & 0,495 \\
\hline & Prop. Bolsa Família & $-0,826$ & 0,268 & $-3,076$ & $<0,0$ I \\
\hline & Log (prop. empregos formais) & 3,476 & 0,779 & 4,464 & $<0,001$ \\
\hline \multirow{7}{*}{$\begin{array}{l}\text { Eleição } \\
2014^{* * *}\end{array}$} & Intercepto & 82,609 & 8,954 & 9,226 & $<0,001$ \\
\hline & Taxa abandono ensino médio 2012 & 0,149 & 0,101 & 1,474 & 0,141 \\
\hline & Índice de envelhecimento & 0,114 & 0,015 & 7,448 & $<0,001$ \\
\hline & Log (PIB per capita) & $-3,536$ & 0,998 & $-3,541$ & $<0,001$ \\
\hline & Partido prefeito eleito em 2012 & $-0,912$ & 0,709 & $-1,287$ & 0,198 \\
\hline & Prop. Bolsa Família & 0,415 & 0,198 & 2,096 & $<0,05$ \\
\hline & Log (prop. empregos formais) & 2,98 & 1,1 & 2,71 & $<0,0$ l \\
\hline
\end{tabular}

1 Todos os valores significativos a $p<0,05$.

* Resultados do modelo para 2002: (F7,635=12,39, $p<0,001$, Radj2 $=0,11)$.

** Resultados do modelo para 2010: (F8,635=16,9I, $p<0,001$, Radj2 $\left.^{2}=0,16\right)$.

*** Resultados do modelo para 20 I4: (F6,538=13,39, $p<0,001$, Radj $\left.^{2}=0,12\right)$.

Fontes: TSE, IBGE, SEADE e processamento da autora.

Outro dado relevante do modelo de 2002 é que quanto maioro índi- 
ce de Gini municipal, maior se mostrou a proporção de votos em Alckmin, mantendo-se as outras variáveis constantes. Ou seja, municípios com maior concentração de renda e, por consequência, com populaçóes mais desiguais entre si, apresentaram nesse ano uma maior proporção de votos em Alckmin.

Os resultados obtidos pelo modelo referente às eleiçóes de 2010 foram, em certa medida, semelhantes aos apresentados em 2002. Em 2010, o IDHM e o índice de Gini tiveram o mesmo efeito de 2002: quanto maior foi o grau de desenvolvimento do município, houve uma queda na proporçáo de votos e, ao passo que a concentração de renda aumentou, a proporção de votos tendeua crescer, mantendo-se ambas as variáveis constantes. $\mathrm{O}$ efeito do índice de envelhecimento também pode ser interpretado da mesma forma que em 2002. O aumento da população mais velha no município tendeu a acarretar o crescimento da proporção de votos em Alckmin na eleição de 2010.

A taxa de analfabetismo, que não havia sido significante estatisticamente em 2002, mostrou-se importante em 2010, de modo que conforme ela aumentou, a proporçáo de votos em Alckmin tendeu a decrescer no município, mantendo as outras variáveis constantes no modelo. O Índice Paulista de Responsabilidade Social-escolar, embora tenha um grau de significância menor que o da variável taxa de analfabetismo, dá força a esse resultado: quanto maior foi o IPRS-escolar, maior foi a proporção de votos no candidato tucano. Pode-se inferir, portanto, que, vista de forma isolada, quanto menor a escolaridade no município, menora proporção de votos em Geraldo Alckmin.

A variável logaritmo da proporção de empregos formais em 2010 também contribui de forma positiva para a votação no governador. Tem-se que, fixando as demais variáveis, quanto maior a proporção de empregos formais no município, a proporção de votos no tucano aumentou. $\mathrm{O}$ mesmo efeito não ocorre quando se considera a variável proporção de famílias que recebiam o Programa Bolsa Família no município. Conforme essa proporção aumentou, a quantidade de votos em Alckmin tendeu a diminuir, mantendo constantes as demais variáveis.

No modelo feito para as eleiçóes de 2014, quatro variáveis apresentaram significância estatística: índice de envelhecimento, logaritmo do PIB per capita, logaritmo da proporção de empregos formais e proporção de famílias que recebiam o Bolsa Família. As variáveis índice de envelhecimento e logaritmo 
da proporção de empregos formais tiveram o mesmo efeito daquele obtido nos modelos de 2002 e 2010: quanto maior foram, houve uma tendência no crescimento da proporção de votos.

Já a variável proporção de famílias que recebiam o Bolsa Família teve um efeito diferente daquele apresentado em 2010. Mantendo as outras variáveis fixas, a tendência é que quanto maior a proporção de famílias beneficiadas pelo PBF no município em 2014, menor a proporção de votos no candidato do PSDB.

O logaritmo do PIB per capita, de acordo com os dados para 2014, incidiu negativamente sobre a proporção de votos em Geraldo Alckmin. Quanto maioro PIB per capita do município, houve uma tendência na diminuição da proporção de votos no candidato.Cabe ressaltar que o efeito inversamente proporcional que o PIB per capita possui sobre a proporção de votosem Alckmin é o mesmo apresentando pela variável IDHM nos modelos de 2002 e 2010.

Além dos resultados descritos acima, cabe assinalar o quanto os modelos propostos para a verificaçáo das hipóteses colaborarampara o entendimento da proporção de votos dada a Geraldo Alckmin nas eleiçóes de 2002, 2010 e 2014. O $\operatorname{Radj}^{2}$ (R ajustado ao quadrado) é o índice responsável por medir o ajustamento do modelo estatístico em relação aos valores observados na amostra. Conforme disposto na Tabela 10.2, os Radj ${ }^{2}$ dos modelos relativos às três eleiçóes são, respectivamente, $0,11,0,16$ e 0,12 . Isso significa dizer que, especificamente, as variáveis independentes contidas no modelo de 2002 explicam apenas $11 \%$ da variação da proporção de votos dada ao governador. Em 2010, 16\% da variação dos dados consegue ser explicada pelas variáveis independentes. Já em 2014, essa porcentagem é de $12 \%$. Esses números mostram que outros fatores, para além dos indicadores socioeconômicos, devem ser incluídos na compreensão da proporção de votos dada ao tucano eleito em Sáo Paulo.

\section{Considerações finais}

O sucesso eleitoral do PSDB e de seus candidatos ao governo do estado de São Paulo é um fato que vem de longa data, ultrapassando vinte anos de poder ininterruptos. Desde a vitória de Mário Covas no pleito estadual de 1994, o partido conquistou seis mandatos consecutivos - o último com a vitória de Geraldo Alckmin em primeiro turno, com mais de 12 milhóes de 
votos nas eleiçóes de 2014. Tendo em vista a complexidade que ronda a arena política bem como os resultados eleitorais, esse estudo se propôs a contribuir com a discussão acerca das reeleiçóes no Brasil, em especial sobre a manutençáa do poder pelo PSDB no governo de Sáo Paulo, por meio do tucano Geraldo Alckmin.

Partindo da literatura que tem as clivagens sociais como relevantes para a estruturação das organizaçóes partidárias, bem como de suas bases de apoio, procurou-se verificar o peso de indicadores socioeconômicos na explicação das proporções de votos recebidas por Alckmin nos municípios em suas três eleiçôes para governador (2002, 2010 e 2014). Após a consecução de um modelo logístico linear generalizado (GLM) para cada ano eleitoral, utilizando-se como variáveis independentes IDHM, Gini, índice de envelhecimento, entre outras,os resultados obtidos mostraram a significância estatística de alguns desses índices.

Cabe dizer, primeiramente, que o partido do prefeito não foi uma variável estaticamente significante em nenhum dos três modelos. Segundo os dados estatísticos, a filiação do chefe do Executivo municipal a um partido da base governista ou da oposição não interferiu na votação no candidato do governo, Geraldo Alckmin. A ausência de significância estatística da variável prefeito nas votaçóes de candidatos à Presidência da República também foi evidenciada em estudos recentes (NICOLAU, 2014; MARTINS, MANSANO, PARRÉ, PLASSA, 2016).

No entanto, ressalta-se que isso não exclui a possível significância do apoio do prefeito para o êxito eleitoral de Alckmin e de seu partido. Em 2002 e em 2014, por exemplo, sabe-se que Alckmin contou com o apoio de vários prefeitos que, tecnicamente, deveriam apoiar os candidatos ao governo de seus respectivos partidos, que eram adversários do governador na disputa. Em 2002, o coordenador da campanha de Alckmin, Joáo Carlos Meirelles, chegou a dizer que o governador contava com o apoio de 531 dos 615 prefeitos de SP na época ${ }^{10}$, os quais justificavam o apoio dizendo que Alckmin era muito atencioso com as cidades. Nas eleiçóes de 2014, o governador recebeu o apoio de 69 das 92 prefeituras comandadas por peemedebistas no estado ${ }^{11}$.

I0 FOLHA DE S. PAULO, Primeiro Caderno, 16 ago. 2002.

II Ver:<http://politica.estadao.com.br/noticias/eleicoes,prefeitos-do-pmdb-deixam-skaf-e-dao-apoio-a-alckmin- 
$\mathrm{Na}$ ocasião, Paulo Skaf era o candidato do PMDB na disputa pelo governo paulista. Certamente o apoio que Alckmin possui entre os prefeitos municipais extrapola a categorizaçáo feita relativa ao apoio formal.

Com relação às demais variáveis, lembrando que a interpretação do efeito de cada uma delas sobre a proporçáo de votos requer que as demais permaneçam constantes, observou-se que, em 2002 e 2010, quanto maior o IDHM, menor a proporção de votos em Alckmin no município. O mesmo efeito teve o aumento do PIB per capita municipal em 2014 sobre a proporção de votos no candidato. Além disso, quanto maior o índice de Gini em 2002 e 2010, a proporção de votos também tendeu a aumentar. Infere-se, portanto, que a proporção de votos em Geraldo Alckmin tendeu,em todas as suas eleiçóes, a aumentar nos municípios menos desenvolvidos - contrariando a hipótese inicial - e entre aqueles que apresentavam maior concentração de renda em 2002 e 2010.

O índice de envelhecimento foi a única variável que, compondo os três modelos estatísticos, foi significante e teve o mesmo efeito em todos. Quanto maior o grau de envelhecimento no município, a proporção de votos em Geraldo Alckmin tendeu a crescer. Esse achado vai de encontro à literatura que aponta o progressivo envelhecimento das bases de apoio dos partidos de direita e centro (LISI, 2011), o que indica um voto mais conservador por parte da população idosa.

O efeito do recebimento do Programa Bolsa Família (PBF) não demonstrou um padrão relativo à votação recebida por Alckmin, influenciando-a de formas diferentes em 2010 e 2014. Na eleiçáo de 2010, quanto maior a proporção de famílias que recebiam o benefício no município, houve uma tendência na diminuição da votação em Alckmin. De início, esse achado colaborou com a hipótese inicial de que o Bolsa Família, por ser um programa ligado ao Partido dos Trabalhadores, funcionaria como um catalisador de votos para os candidatos petistas em detrimento dos candidatos dos partidos oposicionistas. No entanto, os dados de 2014 não confirmaram essa ideia, pois, nessa eleição, quanto maiora proporção de famílias beneficiadas no município, maior seapresentou a votação em Alckmin. Isso corrobora a ideia apresentada

$-i m p-, 15682 \mid 2>$. 
por Limongi e Guarnieri (2015) de que o PBF, embora seja um facilitador, não é um determinante do voto em candidatos do PT.

Não obstante os modelos tenham revelado a significância estatística de alguns indicadores socioeconômicos na compreensão da votação recebida por Alckmin nos municípios, eles explicaram, separadamente,menos de $20 \%$ da variação das proporçóes de votos, o que pôde ser observado pelo valor do $\mathrm{R}$ ajustado ao quadrado $\left(R^{2}\right.$ adj). Isso significa dizer que a compreensão da votação em Alckmin requer a inclusão de outros aspectos além dos índices socioeconômicos, os quais parecem ter importância superficial na sua explicação. Nos três modelos mais de $80 \%$ da variação dos dados náo se explicou por fatores sociais e econômicos, nem mesmo com a inclusão da variável política partido do prefeito. Cabe, portanto, a estudos posteriores a verificaçáo mais detalhada de quais sejam os outros fatores relacionados ao sucesso eleitoral de Geraldo Alckmin.

\section{Referências}

ALMEIDA, A.; LOPEZ, F. Legisladores, captadores e assistencialistas: a representação política no nível local. Brasília: Instituto de Pesquisa Econômica Aplicada, 2012.

AMES, B. Os entraves da democracia no Brasil. Rio de Janeiro: Editora FGV, 2003.

BAQUERO, M. A vulnerabilidade dos partidos políticos e a crise da democracia na América Latina. Porto Alegre: Editora da UFRGS, 2000.

BEZERRA, M. O. Em nome das "bases": política, favor e dependência pessoal. Rio de Janeiro: Relume-Dumará - NUAP, 1999.

BRAGA, M. S. S. Organização partidária e seleção de candidatos no estado de São Paulo. Opiniáo pública, Campinas, v. 14, n. 2, p. 454-485, novembro, 2008.

CARREIRÃO, Y. S. Ideologia e partidos políticos: um estudo sobre coligações em Santa Catarina. Opiniáo pública, Campinas, v. 12, n. 1, p. 136-163, abr./ maio 2006. 
CARVALHO, N. R. E no início eram as bases: geografia política do voto e comportamento legislativo no Brasil. Rio de Janeiro: Revan, 2003.

CERVI, E. U. Produção legislativa e conexão eleitoral na assembleia legislativa do estado do Paraná. Revista de sociologia política, Curitiba, v. 17, n. 32, p. 159-177, fev. 2009.

FERREIRA, O.S. Comportamento eleitoral em São Paulo. Revista brasileira de estudos políticos, Belo Horizonte, n. 8, 1960.

FREIRE, A. Modelos de comportamento eleitoral. Oeiras: Celta Editora, 2001.

GASPAR, J.; ANDRÉ, I. Portugal geografia eleitoral: 1975 e 1987. In: COELHO, M. B. (Org.), O sistema político e constitucional, Lisboa, Instituto de Ciências Sociais, 1989.

JACOB, C. R. et al.Eleiçóes presidenciais de 2002 no Brasil: uma nova geografia eleitoral? Revista ALCEU, Rio de Janeiro, v. 3, n. 6, p. 287-327, jan./jun. 2033.

LAMOUNIER, B. O voto em São Paulo, 1970-1980. In: LAMOUNIER, B. (Org.). Voto de desconfiança, eleiçóes e mudança política no Brasil: 19701979. São Paulo: Vozes, 1980.

. Comportamento eleitoral em Sáo Paulo: passado e presente. In: CARDOSO, F. C. \& LAMOUNIER, B., Os partidos e as eleiçóes no Brasil. Rio de Janeiro: Paz e Terra, 1975.

LIMONGI, F.; GUARNIERI, F. Competição partidária e voto nas eleiçóes presidenciais no Brasil. Opiniáo Pública, Campinas, v. 21, n. 1, p. 60-86, abr. 2015.

LIMONGI, F.; MESQUITA, L. Estratégia partidária e clivagens eleitorais: as eleições municipais pós-redemocratização. In: KOWARICK, L.; MARQUES, E. Sáo Paulo: novos percursos e atores (sociedade, cultura e política). São Paulo: Ed. 34, Centro de Estudos da Metrópole, 2011. . . Estratégia partidária e preferência dos eleitores: as eleiçóes municipais em São Paulo entre 1985 e 2004. Novos estudos, São Paulo, n. 81, 2008. 
LIPSET, S. M.; ROKKAN, S. Party systems and voter alignments, Nova Iorque, Free Press, 1967.

LISI, M. Os partidos políticos em Portugal: continuidade e transformação. Coimbra: Almedina, 2011.

MANIN, B. As metamorfoses do governo representativo. Revista brasileira de ciências sociais, São Paulo, ano 10, n. 29, 1995.

MARQUES, E. C. Redes sociais, instituiçóes e atores políticos no governo da cidade de Sáo Paulo. São Paulo: Annablume: Fapesp, 2003.

MARTINS, D. et al. Fatores que contribuíram para a reeleição da presidente Dilma Rousseff. Política \& sociedade, Florianópolis, v. 15, n. 32, jan./abr., 2016.

NICOLAU, J. Vermelhos e Azuis:um estudo sobre os determinantes do voto nas eleiçóes presidenciais brasileiras (2002-2010).IX ENCONTRO DA ABCP. Brasília, 2014.

PASQUINO, G. Sistemas políticos comparados. Cascais: Principia, 2005.

PIERUCCI, A. A direita mora do outro lado da cidade. Revista brasileira de ciências sociais, São Paulo, v. 4, n. 10, 1989.

. São Paulo 92, a vitória da direita. Novos estudos, São Paulo, n. 35, 1993.

ROCHA M. M; BARBOSA, C. F. Regras, incentivos e comportamento: as comissóes parlamentares nos países do Cone Sul. Revista de sociologia política, Curitiba, v. 16, n. suplementar, p. 93-104, ago. 2008.

ROMA, C. R. Política de alianças e desempenho eleitoral: um estudo sobre as estratégias de competição do PSDB, 1988-1998. Petrópolis, XXIV ENCONTRO ANUAL DA ANPOCS, 2000.

SAMUELS, D. Determinantes do Voto Partidário em Sistemas Eleitorais Centrados no Candidato: Evidências sobre o Brasil. Dados, Rio de Janeiro, v. 40, n. 3, 1997.

SIMÃO, A. O voto operário em São Paulo. Revista brasileira de estudos políticos, Belo Horizonte, n. 1, 1956. 
SOARES, G. A. D.;TERRON, S. Dois Lulas: a geografia eleitoral da reeleição (explorando conceitos, métodos e técnicas de análise geoespacial). Opiniáo pública, Campinas, v. 14, n. 2, nov. 2008.

STORNI, T. P. Comportamento eleitoral e estratégia partidária: uma análise espaço-temporal das eleiçóes de SP e MG a partir dos conceitos de Inovação e Representação Sociais. Dissertação, Centro de Desenvolvimento e Planejamento Regional da Faculdade de Ciências Econômicas, Universidade Federal de Minas Gerais, Belo Horizonte, 165 p., 2010.

WEFFORT, F. C. Raízes sociais do populismo em São Paulo. Revista civilizaçáo brasileira, Rio de Janeiro, ano 1, n. 2, 1965.

WHITELEY, P.; SEYD, P. High-intensity participation: The Dynamics of Party Activism in Britain. USA: Ann Arbor, The University of Michigan Press, 2002.

\section{Sites acessados:}

<http://static.psdb.org.br/wp-content/uploads/2016/02/Estatuto\%20 2015_12_final.pdf>. Acesso em: 10 jun. 2016.

<http://www.cartacapital.com.br/politica/em-hortolandia-o-psdd-nao-temvez-7597.html>. Acesso em: 10 jun. 2016.

$<$ http://politica.estadao.com.br/noticias/eleicoes, prefeitos-do-pmdb-deixamskaf-e-dao-apoio-a-alckmin-imp-,1568212>.Acesso em: 10 jun. 2016.

Tribunal Superior Eleitoral (TSE): <http://www.tse.jus.br/>. Acesso em: 15 maio 2016.

Instituto Brasileiro de Geografia e Estatística (IBGE): <http://www.ibge.gov. br/home/>. Acesso em: 15 maio 2016.

Fundação Sistema Estadual de Análise de Dados (SEADE): <http://www. seade.gov.br/>. Acesso em: 15 maio 2016.

\section{Periódicos acessados:}

FOLHA DE S. PAULO. Primeiro Caderno, 16 de agosto de 2002. 


\section{Apêndice}

Tabela A.I - Estatísticas descritivas das

variáveis utilizadas nos modelos de cada ano eleitoral

\begin{tabular}{|c|c|c|c|c|c|}
\hline Ano & Variáveis & Média & $\begin{array}{l}\text { Desvio } \\
\text { Padrão }\end{array}$ & Mínimo & Máximo \\
\hline \multirow{7}{*}{2002} & IDHM (2000) & 0,644 & 0,048 & 0,462 & 0,820 \\
\hline & Taxa de analfabetismo & 11,180 & 3,547 & 2,940 & 21,770 \\
\hline & Índice de envelhecimento & 43,971 & 14,824 & 13,180 & 120,490 \\
\hline & Índice de Gini (2000) & 0,522 & 0,058 & 0,356 & 0,766 \\
\hline & IPRS-escolar & 52,253 & 9,306 & 15 & 89 \\
\hline & Partido do prefeito* & 0,565 & 0,496 & 0 & I \\
\hline & $\begin{array}{l}\text { Número de empregos } \\
\text { formais }\end{array}$ & 13346 & |3385 | & 104 & 3360921 \\
\hline \multirow{8}{*}{2010} & IDHM & 0,740 & 0,032 & 0,639 & 0,862 \\
\hline & Taxa de analfabetismo & 7,624 & 2,685 & 1,450 & 17,100 \\
\hline & Índice de envelhecimento & 63,489 & 22,007 & 22,140 & 158,730 \\
\hline & Índice de Gini & 0,459 & 0,057 & 0,334 & 0,686 \\
\hline & IPRS-escolar & 51,704 & 8,847 & 22 & 78 \\
\hline & Partido do prefeito* & 0,394 & 0,489 & 0 & I \\
\hline & $\begin{array}{l}\text { Número de empregos } \\
\text { formais }\end{array}$ & 19959,080 & 194441,780 & 159 & 4873339 \\
\hline & $\begin{array}{l}\text { Número de famílias que } \\
\text { recebem Bolsa Família }\end{array}$ & 1821,460 & 7377,690 & 24 & 166137 \\
\hline \multirow{6}{*}{2014} & $\begin{array}{l}\text { Taxa de abandono do } \\
\text { ensino médio (2012) }\end{array}$ & 5,368 & 3,487 & 0,100 & 27,000 \\
\hline & PIB per capita & 22624,599 & 18527,990 & 7232,600 & 283589,470 \\
\hline & Índice de envelhecimento & 76,244 & 26,0550 & 30,130 & 194,690 \\
\hline & Partido do prefeito* & 0,553 & 0,498 & 0 & I \\
\hline & $\begin{array}{l}\text { Número de empregos } \\
\text { formais }\end{array}$ & 21369,830 & 208852,700 & 204 & 5237258 \\
\hline & $\begin{array}{l}\text { Número de famílias que } \\
\text { recebem Bolsa Família }\end{array}$ & 1981,990 & 11534,770 & 27 & 281067 \\
\hline
\end{tabular}

* Variável binária, categorizada da seguinte forma: valor 0, caso o partido seja da base do governo, e I, caso o partido seja de oposição. Fonte: elaboração da autora a partir dos dados do IBGE e SEADE 


\section{Tucanos in the Government of São Paulo: the weight of municipal socioeconomic indicators in the vote for Geraldo Alckmin in the 2002, 2010 and 2014 elections}

\section{Abstract}

The electoral success of PSDB and its candidates for the governorship of the state of São Paulo goes back a long way.This study aims to contribute to the discussion regarding that party's maintenance of political power in that state.From the formulation of three generalized linear logistic models (GLM) - one for each election -, we assessed the relevance of indicators such as years of education and Gini coefficient to the variation in data relating to vote proportionobtainedmunicipally by thePSDB candidate. The researchwas used the 2002,2010 and 2014 elections, which have in common theGeraldo Alckmin's victory. We have concluded that even though statistical models of each electoral year indicated some socioeconomic indicators - such HDI, aging index, and Gini coefficient - as significant to Alckmin's votes, they clarify very little about the total variation in vote proportion. That demonstrated that other contextual factors, unrelated to socioeconomic structure, do have an impact on Alckmin's electoral success in São Paulo.

Keywords: Election. São Paulo.Governor. Socioeconomic indicators.

Recebido em 20/02/2016 Aceito em 10/11/2016 